\title{
High dietary niacin intake is associated with decreased chromosome translocation frequency in airline pilots
}

\author{
Lee C. Yong ${ }^{1,2 *}$ and Martin R. Petersen ${ }^{1}$ \\ ${ }^{1}$ The National Institute for Occupational Safety and Health, CDC, Cincinnati, OH, USA \\ ${ }^{2}$ Industrywide Studies Branch, Division of Surveillance, Hazard Evaluations and Field Studies, National Institute for \\ Occupational Safety and Health, 4676 Columbia Parkway, Mailstop R-15, Cincinnati OH 45226, USA
}

(Received 2 July 2010 - Revised 25 August 2010 - Accepted 26 August 2010 - First published online 8 October 2010)

\section{Abstract}

Experimental studies suggest that B vitamins such as niacin, folate, riboflavin, vitamin $\mathrm{B}_{6}$ and vitamin $\mathrm{B}_{12}$ may protect against DNA damage induced by ionising radiation (IR). However, to date, data from IR-exposed human populations are not available. We examined the intakes of these B vitamins and their food sources in relation to the frequency of chromosome translocations as a biomarker of cumulative DNA damage, in eighty-two male airline pilots. Dietary intakes were estimated by using a self-administered semi-quantitative FFQ. Translocations in peripheral blood lymphocytes were scored by using fluorescence in situ hybridisation whole-chromosome painting. Negative binomial regression was used to estimate rate ratios and $95 \% \mathrm{CI}$, adjusted for age and occupational and lifestyle factors. We observed a significant inverse association between translocation frequency and dietary intake of niacin $(P=0 \cdot 02)$ : adjusted rate ratio for subjects in the highest tertile compared with the lowest tertile was 0.58 (95\% CI $0.40,0.83$ ). Translocation frequency was not associated with total niacin intake from food and supplements as well as dietary or total intake of folate, riboflavin or vitamin $\mathrm{B}_{6}$ or $\mathrm{B}_{12}$. However, the adjusted rate ratios were significant for subjects with $\geq$ median compared with $<$ median intake of whole grains $(P=0.03)$ and red and processed meat $(P=0.01): 0.69$ (95\% CI $0.50,0.96)$ and $1.56(95 \%$ CI $1 \cdot 13,2 \cdot 16)$, respectively. Our data suggest that a high intake of niacin from food or a diet high in whole grains but low in red and processed meat may protect against cumulative DNA damage in IR-exposed persons.

\section{Key words: Niacin: Vitamin B: Chromosome translocations: Airline pilots: Radiation exposure}

$\mathrm{B}$ vitamins such as folate, riboflavin and vitamins $\mathrm{B}_{6}$ and $\mathrm{B}_{12}$, either independently or via the metabolism of folate, are precursors of coenzymes that are involved in the synthesis and methylation of $\mathrm{DNA}^{(1-4)}$. Deficiency in these $\mathrm{B}$ vitamins can result in excessive misincorporation of uracil into DNA, with subsequent DNA strand breaks that can lead to the formation of chromosome aberrations if unrepaired $^{(1,2,5)}$. Niacin, another B vitamin which occurs in two forms (nicotinic acid and nicotinamide), also contributes to the maintenance of DNA integrity due to several important roles. In particular, niacin as a precursor of NAD is required for DNA synthesis as well as the activity of the enzyme, poly(ADP-ribose)polymerase-1, which is important for efficient DNA repair, especially in response to DNA strand breaks induced during cellular genotoxic and oxidative stress ${ }^{(4,6,7)}$.

Ionising radiation (IR), an established human carcinogen ${ }^{(8)}$, is another factor that causes DNA strand breaks either by causing direct damage to DNA or via the formation of reactive oxygen species ${ }^{(9,10)}$. IR is an efficient inducer of chromosome aberrations ${ }^{(11)}$ which have also been shown to be associated with increased cancer risk in prospective studies ${ }^{(12)}$. There is evidence from experimental (in vitro and animal) studies that folate ${ }^{(13,14)}$ and niacin $^{(15-19)}$ may protect against several forms of DNA damage induced directly by IR or via reactive oxygen species-induced oxidative damage. However, to date, there have been no supporting data from IR-exposed human populations.

Airline pilots are exposed to elevated levels of cosmic IR and are considered an IR-exposed occupational group in many countries ${ }^{(20)}$. Translocations, a stable form of chromosome aberrations, which persist through cell divisions, are an established biomarker of cumulative exposure to chronic and low-dose $\mathrm{IR}^{(21)}$. We have previously reported that the translocation frequency in airline

Abbreviation: IR, ionising radiation. 
pilots increased significantly with an increase in the duration of their flight experience in years after adjustment for age and other potential confounders ${ }^{(22)}$. Additionally, the dietary intakes of vitamin $\mathrm{C}, \boldsymbol{\beta}$-carotene, $\beta$-cryptoxanthin and lutein-zeaxanthin, particularly in combination with vitamin $\mathrm{E}$, as well as specific fruit and vegetables were found to have a protective effect on translocation frequency ${ }^{(23)}$. In the present study, we examined further the association between the translocation frequency of these pilots, as a biomarker of cumulative DNA damage, and the intakes of $\mathrm{B}$ vitamins and their food sources, adjusted for potential confounders.

\section{Subjects and methods}

\section{Study subjects}

Details of the design and methods of this biomarker study of cosmic radiation exposure and DNA damage have been reported previously ${ }^{(22,23)}$. Briefly, eighty-three male pilots aged 35-56 years from a major US airline were enrolled in the study between December 2001 and September 2002. Selection was based on the duration of employment and years of flying international flights to ensure that there was a wide range of occupational cosmic radiation exposures. Additionally, the subjects were either a neversmoker (defined as a person who smoked a lifetime total of $<100$ cigarettes) or a light smoker (defined as a smoker who had not smoked in the last 10 years or who was presently smoking $<10$ cigarettes/d); had no personal history of cancer (except nonmelanoma skin cancer), chemotherapy or radiotherapy (except routine diagnostic X-ray procedures); and had no family history of chromosomal instability disorders.

All the subjects provided a venepuncture blood sample and completed self-administered questionnaires on demographics, health and medical history, occupational history (including flight and military experience), height, weight, smoking and alcohol consumption history, recreational activity, personal diagnostic X-ray procedures and diet. After the exclusion of a pilot with an implausible total energy intake of $>17585 \mathrm{~kJ}(4200 \mathrm{kcal})) / \mathrm{d}$, eighty-two pilots remained for the present analysis. The present study was conducted according to the guidelines laid down in the Declaration of Helsinki, and all procedures involving human subjects were approved by the Human Subjects Review Boards of the National Institute for Occupational Safety and Health and the National Cancer Institute. A written informed consent was obtained from all the subjects.

\section{Assessment of dietary intake}

A 138-item (foods and beverages, including coffee and tea) semi-quantitative FFQ developed by Willett et al. ${ }^{(24)}$ was used to assess the usual diet. The subjects were asked about the average frequency of consumption of a given unit or portion size for each item using the past year as a reference period. There were nine possible responses ranging from 'never or less than once per month' to 'six or more per d'. Dietary intakes of folate, riboflavin, vitamins $\mathrm{B}_{6}$ and $\mathrm{B}_{12}$ and niacin were computed by multiplying the frequency of consumption of each item by the nutrient content of the portion specified and then summing over all items. The food composition values were derived from the nutrient database of the US Department of Agriculture $^{(25)}$ and supplemented with manufacturer information.

The FFQ also collected information on the use of multivitamin (brand, type, frequency and duration) and individual vitamin (dose and duration) supplements. The total intake of each B vitamin was calculated by adding the intake from the present use of multivitamin and/or the individual B vitamin supplement to the intake from food. In addition, total folate intake, expressed as dietary folate equivalents, was calculated by first multiplying synthetic folate by a conversion factor of 1.7 before adding to the intake of natural food folate. This conversion is necessary because the synthetic form of folate (i.e. folic acid) from supplements and fortification in food is more bioavailable than the naturally occurring folate from food ${ }^{(26)}$.

The intakes of the major food sources of the $\mathrm{B}$ vitamins were calculated by summing the intakes (in servings/ week) across the foods belonging to each group. Grain products were categorised a priori according to the methods of Jacobs et al. ${ }^{(27)}$ as follows: (1) whole grains included brown rice, dark bread, whole-grain ready-toeat breakfast cereals (with $\geq 25 \%$ whole-grain or bran content by weight as evaluated by package label), popcorn, cooked oatmeal or other cooked cereals, wheat germ, bran and other grains; (2) refined grains included white rice, white or pita bread, refined-grain breakfast cereal, pasta, pizza, English muffins, bagels or rolls and pancakes or waffles; (3) all grains included whole and refined grains; (4) desserts or sweets included doughnuts, brownies, muffins or biscuits, and home- or ready-made cookies, cakes, sweet rolls or other pastry and pies.

Foods in the meat group were categorised a priori as follows: (1) all meat included processed meat (e.g. sausage, salami and bologna), bacon, hot dogs, liver, hamburger, chicken or turkey with or without skin, and beef, pork or lamb as a main or mixed dish or as a sandwich; (2) red meat included all meat minus chicken or turkey; (3) total processed meat included processed meat, bacon and hot dogs. Other food sources of the $\mathrm{B}$ vitamins were categorised as follows: (1) dairy products included milk (skimmed, low fat or whole), ice cream, yogurt, cottage cheese, hard cheese and butter; (2) legumes included dried beans, peas and tofu; (3) seafood included canned tuna, shell fish (e.g. shrimp, lobster, scallops and clams), dark-meat fish and other fish; (4) nuts included peanut butter, peanuts and other nuts; (5) eggs. 


\section{Assay for chromosome translocations}

Chromosome translocations in peripheral blood lymphocytes were analysed using the established cytogenetic method of fluorescence in situ hybridisation with wholechromosome paints as described in detail previously ${ }^{(22)}$. Preparation of cell cultures and slides was performed using standardised methods ${ }^{(28,29)}$. Chromosomes 1, 2 and 4 were painted red, and chromosomes 3, 5 and 6 were simultaneously painted green. The slides were then counterstained with 4',6-diamidino-2-phenylindole. Approximately 1800 cells in metaphase were evaluated for translocations for each subject, which yields information equivalent to 1000 cells in metaphase, as if the full genome had been scored (defined as cell equivalents). The translocations in all cells of each subject were counted and totalled as the translocation frequency. In order to permit comparisons among the subjects, the translocation frequency was converted to the full genome level, i.e. expressed per 100 cell equivalents/subject.

\section{Statistical analyses}

Descriptive statistics (percentage or geometric mean and standard error) were first calculated for age, lifestyle factors, nutrient intakes and duration of flight experience in years ('flight years') among tertiles of the individual dietary $\mathrm{B}$ vitamin intake. Spearman correlation coefficients, $r_{\mathrm{s}}$, were also calculated among the $\mathrm{B}$ vitamins to determine their inter-relationships. Continuous variables were compared by ANOVA or ANCOVA to adjust for age, whereas categorical variables were compared by the $\chi^{2}$ or Fisher's exact test. To account for the correlation of the nutrient intake with energy, all intakes were adjusted for total energy intake using the residual method ${ }^{(30)}$ before all the analyses.

Separate negative binomial regression models were used to assess the relationship between the frequency of translocations (as the dependent variable) and the intakes of the $\mathrm{B}$ vitamins and their food sources. Negative binomial regression was selected because it provides an efficient approach for the control of over-dispersion of the count data of translocation frequency, which can result in an increased unexplained variance and biased standard errors for the parameter estimates ${ }^{(31)}$. Before the analyses, the energy-adjusted nutrient intakes were categorised into tertiles based on the distribution of all the subjects. This was to avoid assumptions about the shape of the nutrient intake-translocation frequency relationship and to provide sufficient power to compare the subjects in the extreme categories of intake. Rate ratios with Wald 95\% CI were estimated for the categories of nutrients or their food sources relative to a reference category. The $P$ values for the likelihood ratio $\chi^{2}$ statistic were also calculated since it is preferable for small sample sizes.
All the regression models were adjusted for flight years (quartiles: $<13 \cdot 2,13 \cdot 2-17 \cdot 4,17 \cdot 5-23 \cdot 2$ or $\geq 23 \cdot 3$ ) as well as for known confounders ${ }^{(22)}$ : age at blood draw $(\leq 40$, $41-45,46-50$ or $>50$ years), cumulative red bone marrow X-ray dose score $(<0.5,0 \cdot 5-1.9$ or $\geq 2 \cdot 0)$, as calculated by Yong et al. ${ }^{(22)}$, and military flying (yes or no). Additional adjustments were made for the following lifestyle factors: pack-years of cigarette smoking, alcohol intake, months of vigorous recreational activity and BMI $\left(\mathrm{kg} / \mathrm{m}^{2}\right)$ as continuous variables. Total energy intake was also included in all the models to account for confounding and to reduce the measurement errors due to general overreporting or under-reporting of food intake in the $\mathrm{FFQ}^{(30)}$. All the statistical tests were two sided and a $P$ value $<0.05$ was considered statistically significant. The analyses were performed using SAS software (version 9.2; SAS Institute, Inc., Cary, NC, USA).

\section{Results}

Table 1 presents the age, percentage of multivitamin supplement use, military flying and former cigarette smoking as well as selected age-adjusted characteristics of the subjects according to the lowest and highest tertile of the energy-adjusted dietary vitamin B intakes. Subjects in each tertile were similar with respect to age, present use of multivitamin supplements, having flown in the military, BMI, months of vigorous recreational activity, intake of alcohol, number of flight years and the cumulative red bone marrow X-ray dose score. A significantly higher percentage of former cigarette smokers was observed for those with a higher intake of folate and riboflavin, including pack-years for riboflavin. There was a tendency (sometimes significant) for a high intake of most of the B vitamins to be associated with a lower intake of saturated fat, but higher intakes of protein and fibre. Additionally, a higher intake of each $\mathrm{B}$ vitamin was observed for those with a higher intake of the other $\mathrm{B}$ vitamins. The intakes of all $\mathrm{B}$ vitamins were significantly correlated $(P<0.05)$ except for folate and vitamin $\mathrm{B}_{12}\left(r_{\mathrm{s}}=0 \cdot 15, P=0 \cdot 19\right)$.

Table 1 also examines the age-adjusted intakes (servings/week) of the major food sources according to the lowest and highest tertile of the energy-adjusted dietary vitamin B intakes. In general, a higher intake of the B vitamins was associated with a higher intake of grain products (except for desserts), and this was significant for folate (for all grains) and niacin (for whole grains). There was a pattern (sometimes significant) of an association of higher intakes of folate, riboflavin, vitamin $\mathrm{B}_{6}$ and niacin, but a lower intake of vitamin $\mathrm{B}_{12}$ with a lower intake of meat. However, this varies with the type of meat: a significantly higher intake of folate, vitamin $\mathrm{B}_{6}$ and niacin was observed for those with a lower intake of red or/and processed meat, but a pattern of a higher intake of vitamin $\mathrm{B}_{12}$ was observed for those with a higher intake of all types of meat. A significantly higher intake of some of the 
Table 1. Selected characteristics for the lowest (T1) and highest (T3) tertile of energy-adjusted dietary vitamin B intake among airline pilots $\dagger$ (Percentages or geometric means with their standard errors, $n$ 82)

\begin{tabular}{|c|c|c|c|c|c|c|c|c|c|c|c|c|c|c|c|}
\hline \multirow[b]{2}{*}{ Covariates } & \multicolumn{3}{|c|}{ Folate $(\mu \mathrm{g} / \mathrm{d})$} & \multicolumn{3}{|c|}{ Riboflavin (mg/d) } & \multicolumn{3}{|c|}{ Vitamin $B_{6}(\mathrm{mg} / \mathrm{d})$} & \multicolumn{3}{|c|}{ Vitamin $B_{12}(\mu \mathrm{g} / \mathrm{d})$} & \multicolumn{3}{|c|}{ Niacin $(\mathrm{mg} / \mathrm{d})$} \\
\hline & T1 & T3 & $\mathrm{SE}$ & T1 & T3 & SE & T1 & T3 & $\mathrm{SE}$ & T1 & T3 & SE & T1 & T3 & SE \\
\hline Age (years) & $45 \cdot 3$ & 47.9 & $1 \cdot 2$ & $46 \cdot 7$ & $46 \cdot 7$ & 1.0 & $45 \cdot 9$ & $46 \cdot 8$ & $1 \cdot 0$ & $46 \cdot 3$ & 46.5 & $1 \cdot 0$ & $46 \cdot 3$ & $47 \cdot 8$ & 1.0 \\
\hline Present multivitamin supplement use (\%) & 63.0 & 63.0 & - & $64 \cdot 3$ & 53.6 & - & $55 \cdot 6$ & $66 \cdot 7$ & - & 71.4 & $50 \cdot 0$ & - & $53 \cdot 6$ & $75 \cdot 0$ & - \\
\hline Military flying (\%) & 63.0 & $77 \cdot 8$ & - & 71.4 & 71.4 & - & $70 \cdot 4$ & $74 \cdot 1$ & - & 78.6 & $60 \cdot 7$ & - & $64 \cdot 3$ & $75 \cdot 0$ & - \\
\hline Former cigarette smokers (\%) & $14 \cdot 8$ & $33 \cdot 3^{*}$ & - & $17 \cdot 9$ & $35 \cdot 7^{\star}$ & - & $7 \cdot 4$ & $29 \cdot 6$ & - & $10 \cdot 7$ & $21 \cdot 4$ & - & $14 \cdot 3$ & $25 \cdot 0$ & - \\
\hline \multicolumn{16}{|l|}{ Age-adjusted } \\
\hline BMI $\left(\mathrm{kg} / \mathrm{m}^{2}\right)$ & $27 \cdot 1$ & $25 \cdot 7$ & 1.0 & $26 \cdot 6$ & $25 \cdot 9$ & $1 \cdot 0$ & $26 \cdot 8$ & $25 \cdot 8$ & 1.0 & $26 \cdot 7$ & $26 \cdot 2$ & $1 \cdot 0$ & 25.9 & $26 \cdot 1$ & 1.0 \\
\hline Vigorous recreational activity (month/year) & $8 \cdot 8$ & 9.5 & $1 \cdot 2$ & $7 \cdot 3$ & $9 \cdot 1$ & $1 \cdot 2$ & 9.5 & $10 \cdot 3$ & $1 \cdot 2$ & $9 \cdot 3$ & $7 \cdot 3$ & $1 \cdot 2$ & $9 \cdot 8$ & $9 \cdot 1$ & $1 \cdot 2$ \\
\hline Alcohol intake $(\mathrm{g} / \mathrm{d})$ & $5 \cdot 0$ & $6 \cdot 8$ & 1.5 & $4 \cdot 0$ & 6.5 & 1.5 & 6.8 & $6 \cdot 0$ & 1.5 & $5 \cdot 7$ & 3.4 & 1.5 & 4.8 & $6 \cdot 2$ & 1.5 \\
\hline Flight years & $15 \cdot 8$ & $16 \cdot 5$ & 1.1 & $16 \cdot 1$ & $17 \cdot 3$ & $1 \cdot 1$ & $16 \cdot 2$ & $15 \cdot 8$ & $1 \cdot 1$ & $16 \cdot 1$ & $17 \cdot 4$ & $1 \cdot 1$ & $16 \cdot 2$ & $15 \cdot 7$ & $1 \cdot 1$ \\
\hline Cumulative red bone marrow $\mathrm{X}$-ray dose score & 0.6 & 0.6 & $1 \cdot 3$ & 0.6 & 0.5 & $1 \cdot 3$ & 0.5 & 0.5 & $1 \cdot 3$ & 0.9 & 0.5 & $1 \cdot 2$ & 0.5 & 0.7 & $1 \cdot 3$ \\
\hline Pack-years & 0.03 & 0.05 & $1 \cdot 6$ & 0.03 & $0.07^{*}$ & 1.5 & 0.02 & 0.05 & $1 \cdot 6$ & 0.02 & 0.03 & $1 \cdot 6$ & 0.02 & 0.04 & $1 \cdot 6$ \\
\hline \multicolumn{16}{|l|}{ Dietary intakeł } \\
\hline Saturated fat $(g / d)$ & $25 \cdot 2$ & $19 \cdot 5^{*}$ & 1.0 & $23 \cdot 3$ & $22 \cdot 2$ & $1 \cdot 0$ & 24.5 & $20 \cdot 7^{*}$ & 1.0 & 21.5 & $23 \cdot 8$ & $1 \cdot 0$ & 23.7 & $21 \cdot 6$ & 1.0 \\
\hline Total protein $(\mathrm{g} / \mathrm{d})$ & 81.3 & $82 \cdot 8$ & 1.0 & $76 \cdot 7$ & $88 \cdot 3^{*}$ & 1.0 & $76 \cdot 8$ & $89.1^{*}$ & 1.0 & $76 \cdot 8$ & $86 \cdot 1^{*}$ & 1.0 & 73.1 & $93 \cdot 4^{*}$ & 1.0 \\
\hline Fibre $(g / d)$ & $16 \cdot 2$ & $22 \cdot 2^{*}$ & $1 \cdot 1$ & $18 \cdot 1$ & $18 \cdot 2$ & $1 \cdot 0$ & $16 \cdot 3$ & $21 \cdot 0^{*}$ & $1 \cdot 1$ & $19 \cdot 7$ & 18.5 & $1 \cdot 1$ & 17.5 & $19 \cdot 9$ & $1 \cdot 1$ \\
\hline Niacin (mg/d) & $22 \cdot 6$ & $27 \cdot 2^{*}$ & 1.0 & 22.4 & $27 \cdot 1^{*}$ & $1 \cdot 0$ & $21 \cdot 8$ & $28 \cdot 7^{\star}$ & 1.0 & 22.9 & $26 \cdot 0$ & $1 \cdot 0$ & $20 \cdot 3$ & $30 \cdot 4^{*}$ & 1.0 \\
\hline Folate $(\mu \mathrm{g} / \mathrm{d})$ & $300 \cdot 6$ & $522 \cdot 2^{*}$ & 1.0 & 344.0 & $458 \cdot 7^{*}$ & $1 \cdot 0$ & $346 \cdot 1$ & $484 \cdot 5^{\star}$ & 1.0 & 369.3 & $414 \cdot 0$ & 1.1 & $351 \cdot 2$ & $437 \cdot 3^{*}$ & 1.0 \\
\hline Riboflavin (mg/d) & 1.6 & $2 \cdot 3^{*}$ & $1 \cdot 0$ & 1.5 & $2 \cdot 5^{\star}$ & $1 \cdot 0$ & 1.6 & $2 \cdot 3^{*}$ & $1 \cdot 0$ & 1.6 & $2 \cdot 1^{*}$ & $1 \cdot 0$ & 1.7 & $2 \cdot 2^{*}$ & 1.0 \\
\hline Vitamin $B_{6}(\mathrm{mg} / \mathrm{d})$ & $1 \cdot 8$ & $2 \cdot 5^{\star}$ & 1.0 & $1 \cdot 8$ & $2 \cdot 4^{*}$ & $1 \cdot 0$ & $1 \cdot 7$ & $2 \cdot 6^{*}$ & $1 \cdot 0$ & 1.9 & $2 \cdot 2^{*}$ & $1 \cdot 0$ & 1.9 & $2 \cdot 4^{*}$ & 1.0 \\
\hline Vitamin $B_{12}(\mu \mathrm{g} / \mathrm{d})$ & 4.9 & $5 \cdot 8$ & $1 \cdot 1$ & $4 \cdot 2$ & $7 \cdot 3^{*}$ & $1 \cdot 1$ & $4 \cdot 4$ & $6 \cdot 1^{*}$ & $1 \cdot 1$ & $3 \cdot 6$ & $8 \cdot 3^{*}$ & $1 \cdot 0$ & 4.9 & $6 \cdot 1$ & $1 \cdot 1$ \\
\hline \multicolumn{16}{|l|}{ Food group (servings/week) } \\
\hline \multicolumn{16}{|l|}{ Grain products } \\
\hline All grains & $12 \cdot 1$ & $20 \cdot 1^{*}$ & $1 \cdot 1$ & $14 \cdot 6$ & $19 \cdot 9$ & $1 \cdot 1$ & $13 \cdot 4$ & $19 \cdot 5$ & $1 \cdot 1$ & $17 \cdot 9$ & $17 \cdot 4$ & $1 \cdot 1$ & $14 \cdot 0$ & $17 \cdot 8$ & $1 \cdot 1$ \\
\hline Whole grains & $5 \cdot 1$ & 11.0 & 1.3 & $5 \cdot 1$ & $9 \cdot 9$ & $1 \cdot 3$ & $5 \cdot 1$ & $11 \cdot 7$ & $1 \cdot 3$ & 5.9 & $9 \cdot 2$ & 1.3 & $4 \cdot 1$ & $10 \cdot 5^{*}$ & $1 \cdot 3$ \\
\hline Refined grains & $5 \cdot 0$ & $6 \cdot 0$ & $1 \cdot 2$ & $6 \cdot 1$ & $7 \cdot 7$ & $1 \cdot 2$ & $6 \cdot 0$ & $5 \cdot 6$ & $1 \cdot 2$ & 7.4 & $6 \cdot 5$ & $1 \cdot 2$ & $6 \cdot 4$ & 5.4 & $1 \cdot 2$ \\
\hline Desserts or sweets & $4 \cdot 1$ & $1.4^{*}$ & 1.4 & 3.9 & $2 \cdot 8$ & 1.4 & 3.6 & $2 \cdot 0$ & 1.4 & $3 \cdot 3$ & $4 \cdot 0$ & 1.4 & $4 \cdot 3$ & $2 \cdot 3$ & 1.4 \\
\hline \multicolumn{16}{|l|}{ Meat } \\
\hline All & $7 \cdot 8$ & $3 \cdot 2^{*}$ & $1 \cdot 2$ & $6 \cdot 2$ & $5 \cdot 3$ & $1 \cdot 2$ & $6 \cdot 3$ & $4 \cdot 1$ & $1 \cdot 2$ & $5 \cdot 1$ & $5 \cdot 8$ & 1.2 & $5 \cdot 6$ & $5 \cdot 7$ & 1.2 \\
\hline Red & $5 \cdot 9$ & $1 \cdot 2^{*}$ & 1.3 & 4.5 & $2 \cdot 6$ & 1.3 & $5 \cdot 1$ & $1 \cdot 7^{\star}$ & $1 \cdot 3$ & $2 \cdot 9$ & $3 \cdot 3$ & 1.3 & 3.1 & $2 \cdot 6$ & $1 \cdot 3$ \\
\hline Processed & 0.7 & 0.4 & 1.5 & 0.6 & 0.6 & 1.5 & 0.9 & 0.3 & 1.5 & 0.4 & 0.9 & 1.5 & 0.6 & $0.3^{*}$ & 1.4 \\
\hline Red and processed & $14 \cdot 1$ & $5 \cdot 6^{*}$ & 1.3 & $11 \cdot 2$ & 8.4 & 1.3 & $12 \cdot 3$ & 8.3 & 1.3 & 8.2 & $9 \cdot 6$ & 1.3 & 9.9 & 9.5 & 1.3 \\
\hline Legumes & 0.2 & $1 \cdot 0^{*}$ & 1.4 & 0.5 & 0.6 & 1.5 & 0.3 & 0.9 & 1.5 & 0.5 & 0.5 & 1.5 & 0.5 & 0.9 & 1.4 \\
\hline Fruit and vegetables & $17 \cdot 7$ & $28 \cdot 5^{*}$ & $1 \cdot 1$ & $24 \cdot 8$ & $23 \cdot 3$ & $1 \cdot 1$ & $22 \cdot 2$ & $25 \cdot 0$ & $1 \cdot 1$ & $27 \cdot 2$ & $21 \cdot 6$ & $1 \cdot 1$ & $25 \cdot 1$ & $22 \cdot 8$ & $1 \cdot 1$ \\
\hline Dairy products & $13 \cdot 0$ & 6.5 & 1.3 & 6.5 & $16 \cdot 6^{*}$ & $1 \cdot 3$ & 8.2 & $7 \cdot 7$ & $1 \cdot 3$ & 5.5 & $14 \cdot 4$ & 1.3 & $12 \cdot 6$ & 7.4 & $1 \cdot 3$ \\
\hline Eggs & 0.9 & 0.9 & 1.4 & 0.7 & 0.9 & $1 \cdot 4$ & $1 \cdot 2$ & 1.0 & 1.4 & $0 \cdot 8$ & 1.0 & 1.4 & 0.8 & $1 \cdot 3$ & 1.4 \\
\hline Seafood & 0.8 & 0.9 & 1.4 & $0 \cdot 6$ & 0.9 & 1.4 & 0.5 & $1 \cdot 2$ & 1.4 & 0.5 & $1 \cdot 4^{*}$ & 1.4 & $0 \cdot 6$ & $1 \cdot 2$ & 1.4 \\
\hline Nuts & $1 \cdot 8$ & $2 \cdot 0$ & 1.4 & $2 \cdot 2$ & 1.5 & $1 \cdot 3$ & $1 \cdot 7$ & $2 \cdot 1$ & $1 \cdot 3$ & 1.5 & $2 \cdot 0$ & $1 \cdot 3$ & 1.4 & $2 \cdot 5$ & 1.3 \\
\hline
\end{tabular}

${ }^{*}$ Mean values or percentages were significantly different $(P<0.05)$

† Only the geometric SE of T1 is presented because it is similar to that of T3 due to nearly equal sample sizes. $P$ values across all tertiles (unadjusted from ANOVA and age-adjusted from ANCOVA based on log $\mathrm{e}_{\mathrm{e}}$ covariates) were not statistically significant unless noted. For covariates presented as percentages, the $P$ value is from a $\chi^{2}$ or Fisher's exact test.

$\ddagger$ Also adjusted for total energy intake. 
B vitamins was also observed for a higher intake of other food groups: folate with legumes and fruit and vegetables; riboflavin with dairy products; vitamin $\mathrm{B}_{12}$ with seafood.

The results of separate negative binomial regression models relating the translocation frequency with the dietary (food and fortification) and total (dietary plus supplements) intakes of niacin, folate, riboflavin and vitamins $\mathrm{B}_{6}$ and $\mathrm{B}_{12}$ adjusted for potential confounders are shown in Table 2 . Translocation frequency was significantly and inversely associated with dietary niacin intake $(P=0.02)$; the adjusted rate ratio for subjects in the highest compared with the lowest tertile was 0.58 (95\% CI 0.40 , 0.83). Because fortification contributed an estimated $23 \%$ to the dietary intake of folate in this group of subjects, we also examined the association between translocation frequency and the intake from diet (food and fortification) and food (without fortification) separately. An indication of a stronger inverse association was observed for the intake of folate from food only than from the diet that included fortified foods: an adjusted rate ratio for the subjects in the highest tertile compared with those in the lowest tertile was 0.76 (95\% CI $0.51,1.14)$ for food only $v .0 .97$ (95\% CI $0.65,1.43)$ for dietary intake. No associations were observed for the dietary intakes of riboflavin and vitamins $\mathrm{B}_{6}$ and $\mathrm{B}_{12}$; however, data on intake from food only were not available.

In the present study, 22 and $60 \%$ of the subjects reported past and present use of multivitamins, respectively. Present use of the individual B vitamin supplements was only reported for folate $(n 2)$ and vitamin $\mathrm{B}_{6}(n 2)$. Supplements (from present use of multivitamins and/or individual $\mathrm{B}$ vitamin) contributed an estimated 26, 26, 29, 32 and 34\% to the total intake of niacin, folate, riboflavin and vitamins $\mathrm{B}_{6}$ and $\mathrm{B}_{12}$, respectively. We have previously reported that translocation frequency was not associated with the past or present use of multivitamins, even among present users with long duration ( $\geq 5$ years) or high frequency $(>5$ times/week) of use ${ }^{(23)}$. In addition, as shown in Table 2, translocation frequency was not associated with the total intake (dietary plus supplements) of any of the B vitamins, adjusted for potential confounders. For folate, the association was NS for the total intake calculated as either the sum of dietary and supplemental folate or dietary folate equivalents.

The association between translocation frequency and intakes (high $v$. low based on the median intake in servings/week as the cut-off, rounded to the nearest whole number) of the major food sources of the $\mathrm{B}$ vitamins are examined and presented in Table 3. There was a tendency for the adjusted rate ratios to be reduced, but non-significantly for high intakes of dairy products, eggs, seafood and legumes. However, the adjusted rate ratios were significant for the subjects with $\geq$ median compared with $<$ median intake of whole grains $(P=0.03)$ and red and processed meat $(P=0.01): 0.69$ (95\% CI $0.50,0.96)$ and 1.56 (95\% CI $1 \cdot 13,2 \cdot 16)$, respectively.
The statistical significance of the association between translocation frequency and the dietary intake of each of the $\mathrm{B}$ vitamins remained unchanged after the following additional adjustments (data not shown): (1) all vitamin B intakes when introduced simultaneously in the same regression model; (2) multivitamin supplement use; (3) intake of grain products or meat; (4) intake of fruit and vegetables as well as the combined dietary intakes of vitamins $C$ and $E, \quad \beta$-carotene, $\beta$-cryptoxanthin and lutein-zeaxanthin (previously shown to be significantly and inversely associated with translocation frequency) ${ }^{(23)}$. There were also no alterations in the significance when we further adjusted for the dietary intakes of other nutrients that are found in similar food sources (such as fat and protein in meat) or that may affect the requirement of these B vitamins (such as methionine and tryptophan). However, the association was strengthened for the dietary intake of niacin: the adjusted rate ratio for the subjects in the highest tertile compared with those in the lowest tertile when further adjusted for the intake of protein was 0.44 (95\% CI 0.26, 0.76) and for tryptophan was 0.37 (95\% CI $0 \cdot 22,0 \cdot 62$ ) (data not shown).

\section{Discussion}

In the present study of subjects with IR exposure, we observed a significant $42 \%$ decrease in the frequency of chromosome translocations for those with high compared with low dietary (food and fortification) intake of niacin. Translocation frequency was not associated with the dietary intake of folate, riboflavin or vitamin $\mathrm{B}_{6}$ or $\mathrm{B}_{12}$. Additionally, no association was observed for the total (dietary and supplements) intake of any of these B vitamins. These results persisted after the adjustment for potential confounders. To our knowledge, no previous study has examined the intakes of these $\mathrm{B}$ vitamins in relation to translocation frequency as a biomarker of cumulative DNA damage in an IR-exposed human population with which we can directly compare our findings.

Our finding on the significant inverse translocation frequency-dietary niacin intake association may be explained by the important role of niacin in the formation and maintenance of cellular NAD levels ${ }^{(6,7)}$. NAD is the sole substrate for the enzyme, poly(ADP-ribose)polymerase-1, which is involved in DNA repair activity in response to DNA strand breaks. This is supported by in vitro studies indicating that niacin is protective against DNA damage by increasing the resistance of human lymphocytes against the effect of $\mathrm{IR}^{(16)}$ as well as by improving the DNA repair capacity of cells following irradiation ${ }^{(17)}$. Several experimental studies have suggested that niacin may also function as an antioxidant in its protection against reactive oxygen species-induced DNA strand breaks ${ }^{(15,18,19)}$ in addition to being a precursor of $\mathrm{NAD}^{(18)}$. Therefore, from a mechanistic perspective and as was observed in the present study subjects, it could be speculated that a low 
Table 2. Association between energy-adjusted vitamin B intakes and translocation frequency/100 cell equivalents among airline pilots* (Rate ratios and Wald $95 \%$ confidence intervals, $n 82$ )

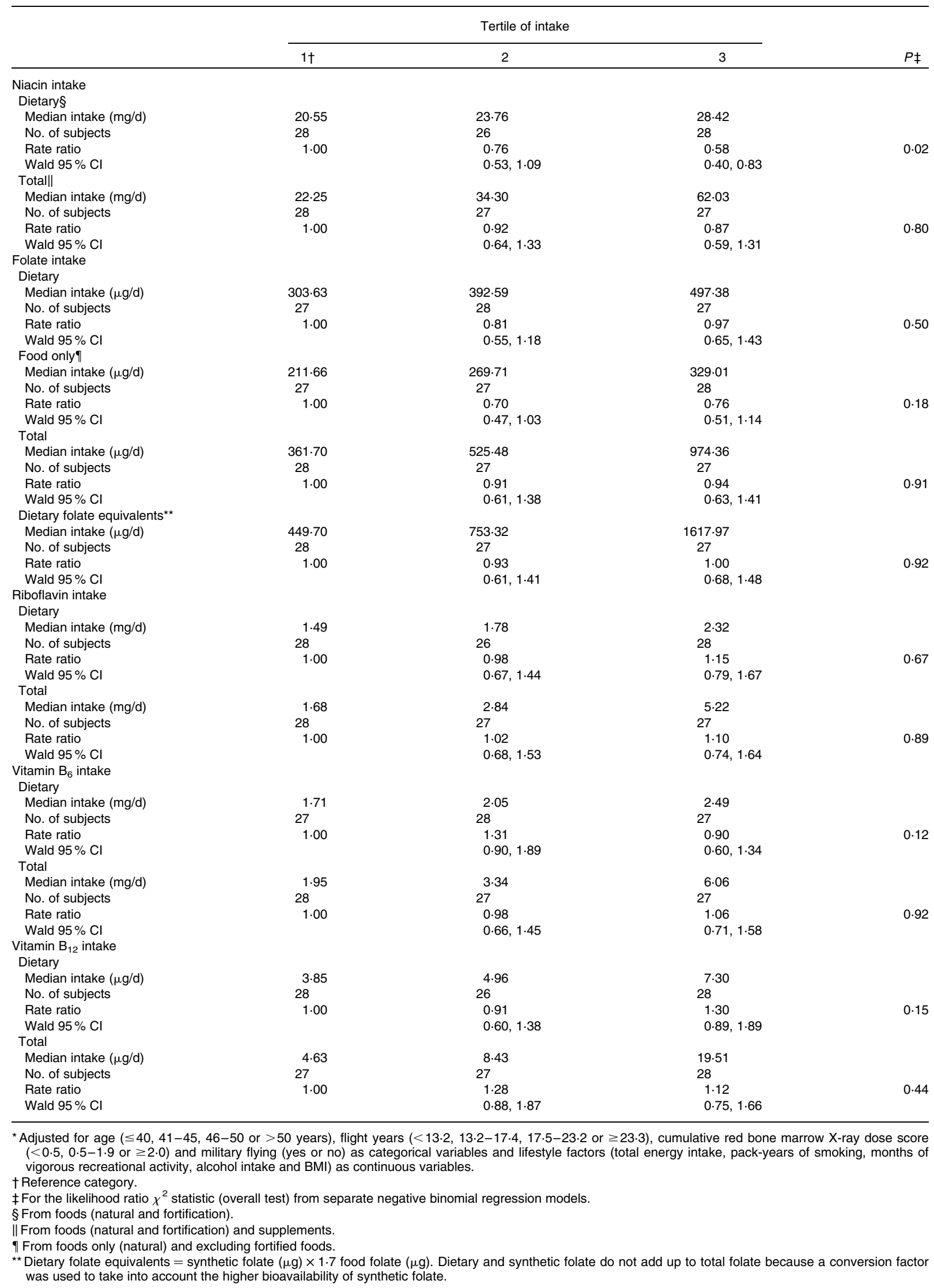


Table 3. Association between intakes of food groups and translocation frequency/100 cell equivalents among airline pilots* (Rate ratios and Wald $95 \%$ confidence intervals, $n 82$ )

\begin{tabular}{|c|c|c|c|c|c|}
\hline Food group & Servings/week $\dagger$ & $n$ & Rate ratio & Wald $95 \% \mathrm{Cl}$ & $P \neq$ \\
\hline \multicolumn{6}{|l|}{ Dairy products } \\
\hline Low intake§ & $<12 \cdot 0$ & 42 & 1.00 & \multirow[b]{2}{*}{$0.68,1.41$} & 0.89 \\
\hline High intake & $\geq 12 \cdot 0$ & 40 & 0.98 & & \\
\hline \multicolumn{6}{|l|}{ Eggs } \\
\hline Low intake & $<1.0$ & 44 & 1.00 & \multirow[b]{2}{*}{$0.68,1.35$} & 0.81 \\
\hline High intake & $\geq 1 \cdot 0$ & 38 & 0.96 & & \\
\hline \multicolumn{6}{|l|}{ Seafood } \\
\hline Low intake & $<1 \cdot 0$ & 39 & 1.00 & \multirow[b]{2}{*}{$0 \cdot 60,1 \cdot 17$} & 0.32 \\
\hline High intake & $\geq 1 \cdot 0$ & 43 & 0.84 & & \\
\hline \multicolumn{6}{|l|}{ Legumes } \\
\hline Low intake & $<1.0$ & 45 & 1.00 & \multirow[b]{2}{*}{$0.61,1.27$} & 0.49 \\
\hline High intake & $\geq 1.0$ & 37 & 0.88 & & \\
\hline \multicolumn{6}{|l|}{ All grains } \\
\hline Low intake & $<17.5$ & 39 & 1.00 & \multirow[b]{2}{*}{$0.48,0.95$} & 0.03 \\
\hline High intake & $\geq 17.5$ & 43 & 0.67 & & \\
\hline \multicolumn{6}{|l|}{ Whole grains } \\
\hline Low intake & $<7.5$ & 34 & 1.00 & \multirow{3}{*}{$0.50,0.96$} & 0.03 \\
\hline High intake & $\geq 7.5$ & 48 & 0.69 & & \\
\hline \multicolumn{5}{|l|}{ Refined grains } & \\
\hline Low intake & $<7.5$ & 44 & 1.00 & \multirow[b]{2}{*}{$0.72,1.49$} & 0.84 \\
\hline High intake & $\geq 7.5$ & 38 & 1.04 & & \\
\hline \multicolumn{6}{|l|}{ All meat } \\
\hline Low intake & $<7.0$ & 42 & 1.00 & \multirow[b]{2}{*}{$0.73,1.68$} & 0.63 \\
\hline High intake & $\geq 7 \cdot 0$ & 40 & $1 \cdot 11$ & & \\
\hline \multicolumn{6}{|l|}{ Red meat } \\
\hline Low intake & $<5.0$ & 42 & 1.00 & \multirow{3}{*}{$1 \cdot 07,2 \cdot 26$} & 0.02 \\
\hline High intake & $\geq 5 \cdot 0$ & 40 & 1.55 & & \\
\hline \multicolumn{5}{|c|}{ Processed meat } & \\
\hline Low intake & $<0.5$ & 27 & 1.00 & \multirow{3}{*}{$1 \cdot 14,2 \cdot 29$} & 0.01 \\
\hline High intake & $\geq 0.5$ & 55 & 1.61 & & \\
\hline \multicolumn{5}{|c|}{ Red and processed meat } & \\
\hline Low intake & $<14.5$ & 42 & 1.00 & \multirow[b]{2}{*}{$1 \cdot 13,2 \cdot 16$} & 0.01 \\
\hline High intake & $\geq 14.5$ & 40 & 1.56 & & \\
\hline
\end{tabular}

*Adjusted for age $(\leq 40,41-45,46-50$ or $>50$ years), flight years $(<13.2,13.2-17.4,17.5-23.2$ or $\geq 23.3)$, cumulative red bone marrow X-ray dose score $(<0.5,0.5-1.9$ or $\geq 2.0)$ and military flying (yes or no) as categorical variables and lifestyle factors (total energy intake, pack-years of smoking, months of vigorous recreational activity, alcohol intake and BMI) as continuous variables.

† On the basis of the median cut-off, rounded to the nearest whole number.

$\ddagger$ For the likelihood ratio $\chi^{2}$ statistic (overall test) from separate negative binomial regression models.

$\S$ Reference category.

compared with a high dietary intake of niacin would be expected to result in a higher accumulation of DNA strand breaks due to impaired DNA repair, which in turn may lead to a higher frequency of translocations.

Substantial evidence from experimental studies suggests that adequate folate status is important for the maintenance of DNA integrity, as folate depletion is associated with DNA strand breaks ${ }^{(1-3,5,32)}$. Folate is required for the synthesis of purine and thymidine nucleotides that are used for DNA synthesis. A deficiency in folate can thus result in an impairment of DNA synthesis via excessive incorporation of uracil instead of thymidine into DNA, which in turn leads to DNA strand breaks and a disruption of the DNA repair mechanism. Furthermore, in the in vitro studies of Chinese hamster ovary cells ${ }^{(13)}$ and human lymphocytes $^{(14)}$, folate deficiency was found to enhance DNA strand breaks induced by IR. However, in this group of human subjects with low and chronic IR exposure, dietary folate intake was observed to have an inverse but NS association with translocation frequency as the endpoint for cumulative DNA damage. A possible explanation could be that since the translocation frequency is dependent on efficient repair of DNA strand breaks, a high intake of niacin rather than folate may be more critical in providing protection against DNA damage during the genotoxic and oxidative stress condition of IR exposure.

Riboflavin and vitamins $\mathrm{B}_{6}$ and $\mathrm{B}_{12}$ are involved as enzymatic cofactors in the folate-mediated metabolic pathway, and their depletion can also cause DNA strand breaks by the same mechanism as for folate ${ }^{(1-3,5,32-34)}$. Therefore, the interrelationship among these metabolically related B vitamins would make it difficult to separate their independent effects. However, our data indicate that translocation frequency was not associated with the dietary intake of riboflavin or vitamin $\mathrm{B}_{6}$ or $\mathrm{B}_{12}$. Additionally, these results, including that of folate or niacin, remained essentially unchanged when adjusted for the intakes of all other B vitamins by being introduced simultaneously in the same regression model.

Although the bioavailability of the synthetic form of folate or vitamin $B_{12}$ in supplements and fortified foods is higher than that of the natural form in foods ${ }^{(35)}$, we 
did not find a significant association between translocation frequency and the higher total (dietary and supplements) intake of folate or vitamin $\mathrm{B}_{12}$. Likewise, no association was observed for the higher total intake of riboflavin or vitamin $\mathrm{B}_{6}$. For niacin, an inverse association was observed for both the dietary and total intake, but this was only significant for the dietary intake with a stronger protective effect. These data suggest that supplements may only be beneficial for those with low intakes from food, as indicated by a non-protective or lesser protective effect for the total compared with the dietary intake. Furthermore, our observation on total niacin intake is supported by other experimental ${ }^{(17)}$ and pharmacological $^{(36)}$ studies, and it has been suggested that further studies are needed to better understand the mechanism by which a high supplemental intake of niacin influences DNA damage or genomic instability ${ }^{(37)}$.

As shown by our data, the dietary intakes of the B vitamins are derived from a variety of food sources, including fortified ready-to-eat cereals, enriched whole-grain products, legumes, fruit and vegetables, dairy products, seafood, eggs, meat and liver ${ }^{(38)}$. Although fortified cereals and grain products are the main food sources of B vitamins, legumes and certain fruit and vegetables are also good sources for folate; legumes for niacin; dairy products and liver for riboflavin; and legumes and seafood for vitamin $\mathrm{B}_{6}$, whereas the only other main source for vitamin $\mathrm{B}_{12}$ is animal based, i.e. from meat, seafood and dairy products $^{(34,35)}$, as was observed in the intakes of our subjects. In addition to being a source of the B vitamins, meat also contains carcinogens such as $N$-nitroso compounds (in processed meat) and heterocyclic amines formed in meat (particularly in red meat) that is cooked at high temperatures ${ }^{(39)}$.

In this group of subjects, the frequency of translocations was decreased by about 30\% for all grain products (for whole but not refined grains) but was increased by $56 \%$ for red and processed meat when comparing the high with the low intake of these foods. Therefore, there is a possibility that the present results for the dietary intakes of the $\mathrm{B}$ vitamins may be attributed to other nutrients as well as protective or harmful factors in similar foods. Although we could not exclude this possibility, the present results for the dietary intakes of the $\mathrm{B}$ vitamins were unaltered when adjusted for the intake of grain products or meat as well as of fruit and vegetables or the combined intakes of vitamins $\mathrm{C}$ and $\mathrm{E}, \beta$-carotene, $\beta$-cryptoxanthin and lutein-zeaxanthin from food (previously shown to be significantly and inversely associated with translocation frequency) $^{(23)}$.

Because of their job requirements and frequent medical surveillance to maintain fitness and health throughout their career $^{(22)}$, airline pilots are more likely to have a better diet than the general population. This is shown by our data where a majority had a dietary intake of the $\mathrm{B}$ vitamins (i.e. 99, 44, 98, 100 and 98\% for niacin, folate, riboflavin and vitamins $\mathrm{B}_{6}$ and $\mathrm{B}_{12}$, respectively) that was higher than the US RDA ${ }^{(38)}$. Furthermore, in the lowest tertile (reference category), the median dietary intake of niacin, riboflavin and vitamins $\mathrm{B}_{6}$ and $\mathrm{B}_{12}$ exceeded the RDA. Therefore, our findings may not be applicable to subgroups of other IR-exposed populations whose intake of these $\mathrm{B}$ vitamins may be considerably lower than that of the airline pilots. It is possible that a protective effect of these B vitamins, except for niacin, may be detected in other IR-exposed populations with broader ranges of intakes that include a group with low or deficient intake for comparison with a high intake group.

There is a possibility that some of our findings on translocation frequency in relation to dietary B vitamin intake may be explained by reasons other than biological factors. We utilised a self-administered FFQ with good reproducibility for the assessment of the diet which had been validated for the intakes of folate and vitamins $\mathrm{B}_{6}$ and $\mathrm{B}_{12}$ in a subset of men of comparable socio-economic status in the Health Professionals' Follow-up Study ${ }^{(24,40)}$. However, the intake of vitamin $\mathrm{B}_{12}$ from the diet may not be a good indicator of status due to its complex absorption process $^{(35)}$, which could explain the lack of association for vitamin $B_{12}$ in our subjects. The dietary requirement of niacin is also influenced by the availability of the amino acid tryptophan in protein ${ }^{(6)}$. Since the association between translocation frequency and dietary intake of niacin was strengthened after adjusting for either protein or tryptophan, this may suggest that it is unlikely that the validity of our finding is affected appreciably by the use of a FFQ for the assessment of its intake. Instead, the large number of food and beverage items in the FFQ would enhance the capture of important sources of these $B$ vitamins that are distributed in a wide variety of foods.

Measurement error of a single self-administered FFQ is unavoidable, but this would more likely result in a greater misclassification of the individual than the group intake based on ranking, particularly when comparing the extreme intake categories, as was done in the present study. Although we were able to adjust for many potential confounders including lifestyle factors, we could not exclude uncontrolled residual confounding or the influence of factors that may affect nutrient availability such as polymorphisms in genes that play a role in the metabolism of these B vitamins. Additionally, our small sample size could possibly have resulted in some real relationships, most likely those fairly close to significance, being missed. However, none of the NS relationships with the $B$ vitamins was monotonically decreasing with fairly low $P$ value, and none of the NS relationships with the food sources had a $P$ value $<0 \cdot 30$. Thus, if relationships were missed, they were most likely weak.

In summary, in this group of airline pilots with dietary intake that predominantly exceeded the present RDA, a high dietary or total intake of folate, riboflavin, or vitamin $\mathrm{B}_{6}$ or $\mathrm{B}_{12}$ was not associated with a decrease in 
translocation frequency. However, a decrease in translocation frequency was associated with a high intake of niacin but this was only significant for the dietary intake. These findings suggest that a high intake of niacin from food or a diet high in whole grains but low in red and processed meat may protect against IR-induced cumulative DNA damage. The present results may be applicable to flight crews worldwide, astronauts in space flights and frequent flyers in the general population. Larger studies of IRexposed populations with broader ranges of intakes that incorporate biomarkers of vitamin B status are needed to further examine the effect modification of the translocation frequency-IR dose association as well as cancer risk by intake of these vitamins.

\section{Acknowledgements}

We thank the airline pilots, whose participation made the present study possible; the staff of Battelle Centers for Public Health Research and Evaluation (particularly Louise Glezen, Katrina Spencer and James Kerrigan) for data collection; Lian Luo (SRA International Inc) for assistance with data programming; Laura A. Sampson (Harvard School of Public Health) for assistance with dietary assessment; and Teresa T. Fung (Simmons College) for consultation on the categorisation of the FFQ food items. The authors' responsibilities were as follows: L. C. Y. developed the study concept and design as well as the statistical analysis plan, performed the analysis, wrote the first draft of the manuscript and obtained funding; and M. R. P. provided the statistical expertise and advice. All the authors contributed to the interpretation of data and writing and approval of the final manuscript. None of the authors had a conflict of interest to declare. The present research was supported in part by an interagency agreement between the National Institute for Occupational Safety and Health and the National Cancer Institute (contract Y1CP802904) and by the Intramural Research Program of the Division of Cancer Epidemiology and Genetics, National Cancer Institute. The findings and conclusions in this report are those of the author(s) and do not necessarily represent the views of the National Institute for Occupational Safety and Health.

\section{References}

1. Ames BN (2001) DNA damage from micronutrient deficiencies is likely to be a major cause of cancer. Mutat Res 475, 7-20.

2. Blount BC, Mack MM, Wehr CM, et al. (1997) Folate deficiency causes uracil misincorporation into human DNA and chromosome breakage: implications for cancer and neuronal damage. Proc Natl Acad Sci U S A 94, 3290-3295.

3. Choi SW \& Mason JB (2000) Folate and carcinogenesis: an integrated scheme. J Nutr 130, 129-132.

4. Jacob RA (1999) The role of micronutrients in DNA synthesis and maintenance. Adv Nutr Cancer 2, 101-113.
5. Duthie SJ, Narayanan S, Brand GM, et al. (2002) Impact of folate deficiency on DNA stability. J Nutr 132, 2444S-2449S.

6. Hageman GJ \& Stierum RH (2001) Niacin, poly(ADP-ribose) polymerase- 1 and genomic stability. Mutat Res 475, 45-56.

7. Kirkland JB (2003) Niacin and carcinogenesis. Nutr Cancer 46, 110-118.

8. International Agency for Research on Cancer (2000) Ionizing radiation part $1: \mathrm{X}$ - and gamma-radiation and neutrons: IARC Monographs on the Evaluation of Carcinogenic Risks to Humans, vol. 75. Lyon: IARC.

9. Fang YZ, Yang S \& Wu G (2002) Free radicals, antioxidants, and nutrition. Nutrition 18, 872-879.

10. Riley PA (1994) Free radicals in biology: oxidative stress and the effects of ionizing radiation. Int J Radiat Biol 65, 27-33.

11. Natarajan AT (1993) Mechanisms for inductions of mutations and chromosomal alterations. Environ Health Perspect 101, Suppl. 3, 225-229.

12. Bonassi S, Norppa H, Ceppi M, et al. (2008) Chromosomal aberration frequency in lymphocytes predicts the risk of cancer: results from a pooled cohort study of 22358 subjects in 11 countries. Carcinogenesis 9, 1178-1183.

13. Branda RF \& Blickensderfer DB (1993) Folate deficiency increases genetic damage caused by alkylating agents and $\gamma$-irradiation in Chinese hamster ovary cells. Cancer Res 53, 5401-5408.

14. Courtemanche C, Huang AC, Elson-Schwab I, et al. (2004) Folate deficiency and ionizing radiation cause DNA breaks in primary human lymphocytes: a comparison. FASEB J 18, 209-211.

15. Kamat JP \& Devasagayam TP (1999) Nicotinamide (vitamin $\mathrm{B}_{3}$ ) as an effective antioxidant against oxidative damage in rat brain mitochondria. Redox Rep 4, 179-184.

16. Kol R \& Ben-Hur E (1983) Radiation protection of stimulated human lymphocytes by nicotinamide. Radiat Environ Biophys 22, 133-140.

17. Riklis E, Kol R \& Marko R (1990) Trends and developments in radioprotection: the effect of nicotinamide on DNA repair. Int J Radiat Biol 57, 699-708.

18. Weitberg AB (1989) Effect of nicotinic acid supplementation in vivo on oxygen radical-induced genetic damage in human lymphocytes. Mutat Res 216, 197-201.

19. Zhang JZ, Henning SM \& Swendseid ME (1993) Poly(ADPribose) polymerase activity and DNA strand breaks are affected in tissues of niacin-deficient rats. J Nutr $\mathbf{1 2 3}$, $1349-1355$.

20. United Nations Scientific Committee on the Effects of Atomic Radiation (UNSCEAR) (2000) Sources and Effects of Ionizing Radiation. Vol. 1. Report to the General Assembly, with Scientific Annexes; United Nations: New York.

21. Tucker JD (2008) Low-dose ionizing radiation and chromosome translocations: a review of the major considerations for human biological dosimetry. Mutat Res 659, 211-220.

22. Yong LC, Sigurdson AJ, Ward EM, et al. (2009) Increased frequency of chromosome translocations in airline pilots with long-term flying experience. Occup Environ Med 66, $56-62$.

23. Yong LC, Petersen MR, Sigurdson AJ, et al. (2009) High dietary antioxidant intakes are associated with decreased chromosome translocation frequency in airline pilots. $\mathrm{Am} \mathrm{J}$ Clin Nutr 90, 1402-1410.

24. Willett WC, Sampson L, Stampfer MJ, et al. (1985) Reproducibility and validity of a semiquantitative food frequency questionnaire. Am J Epidemiol 122, 51-65.

25. U.S. Department of Agriculture, Agricultural Research Service. (2001) USDA Nutrient Database for Standard Reference, Release 14. Nutrient Data Laboratory, Beltsville, MD. 
26. Yang TL, Hung J, Caudill MA, et al. (2005) A long-term controlled folate feeding study in young women supports the validity of the 1.7 multiplier in the dietary folate equivalency equation. $J$ Nutr 135, 1139-1145.

27. Jacobs DR Jr, Meyer KA, Kushi LH, et al. (1998) Whole-grain intake may reduce the risk of ischemic heart disease death in postmenopausal women: the Iowa Women's Health Study. Am J Clin Nutr 68, 248-257.

28. Matsumoto K, Ramsey MJ, Nelson DO, et al. (1998) Persistence of radiation-induced translocations in human peripheral blood determined by chromosome painting. Radiat Res 149, 602-613.

29. Ramsey MJ, Moore DH 2nd, Briner JF, et al. (1995) The effects of age and lifestyle factors on the accumulation of cytogenetic damage as measured by chromosome painting. Mutat Res 338, 95-106.

30. Willett WC \& Stampfer MJ (1998) Implications of total energy intake for epidemiologic analyses. In Nutritional Epidemiology, pp. 273-301 [WC Willett, editor]. New York: Oxford University Press.

31. Lindsey JK (1995) Modelling Frequency and Count Data. Oxford: Oxford University Press.

32. Eto I \& Krumdieck CL (1986) Role of vitamin $B_{12}$ and folate deficiencies in carcinogenesis. Adv Exp Med Biol 206, 313-330.
33. Powers HJ (2003) Riboflavin (vitamin B-2) and health. $A m J$ Clin Nutr 77, 1352-1360.

34. Stover PJ (2004) Physiology of folate and vitamin $B_{12}$ in health and disease. Nutr Rev 62, S3-S12.

35. Allen LH (2008) Causes of vitamin $\mathrm{B}_{12}$ and folate deficiency. Food Nutr Bull 29, S20-S34.

36. Spronck JC \& Kirkland JB (2002) Niacin deficiency increases spontaneous and etoposide-induced chromosomal instability in rat bone marrow cells in vivo. Mutat Res $\mathbf{5 0 8}$, 83-97.

37. Kirkland JB (2009) Niacin status, NAD distribution and ADPribose metabolism. Curr Pharm Des 15, 3-11.

38. Institute of Medicine (2000) Dietary Reference Intakes: Thiamin, Riboflavin, Niacin, Vitamin $B_{6}$, Folate, Vitamin $B_{12}$, Pantothenic Acid, Biotin, and Choline. Washington, DC: Food and Nutrition Board, National Academy Press.

39. World Cancer Research Fund, AICR (2007) Food, Nutrition, Physical Activity and the Prevention of Cancer: A Global Perspective. Washington, DC: AICR.

40. Rimm EB, Giovannucci EL, Stampfer MJ, et al. (1992) Reproducibility and validity of an expanded self-administered semiquantitative food frequency questionnaire among male health professionals. Am J Epidemiol 135, $1114-1126$. 